\title{
Impact of pandemic restrictions on antenatal complications at a tertiary care center
}

\author{
Anshu Baser*, S. Kumar \\ Department of Obstetrics and Gynecology, MGM Kalamboli, Sector 4E, Kalamboli, Navi mumbai, Maharashtra, India
}

Received: 12 January 2021

Revised: 19 February 2021

Accepted: 26 February 2021

\section{*Correspondence:}

Dr. Anshu Baser,

E-mail: anshubaser@gmail.com

Copyright: ( $)$ the author(s), publisher and licensee Medip Academy. This is an open-access article distributed under the terms of the Creative Commons Attribution Non-Commercial License, which permits unrestricted non-commercial use, distribution, and reproduction in any medium, provided the original work is properly cited.

\begin{abstract}
Background: The ongoing pandemic has drastically affected the heath care sector, especially the tertiary care centers taking the major burden of patients. Apart from COVID-19 positive patients there has also been an increase in Covid 19 negative patients due to other private hospitals being closed. We have conducted an analysis at a tertiary care centre comparing the patient data in 3 months that is from $23^{\text {rd }}$ March 2020 to $22^{\text {nd }}$ June 2020 and the same time period last year 2019. The antenatal and postnatal complications and mode of delivery were analysed.

Methods: A total of 1837 cases were compared. Patients were divided into 2 groups case and controls

Control group comprised of 780 patients admitted between $23^{\text {rd }}$ March 2019 to $22^{\text {nd }}$ June 2019. Case group consisted of 1057 patients admitted between $23^{\text {rd }}$ March 2020 to $22^{\text {nd }}$ June 2020 . Patient were matched for age, parity, socioeconomic and demographic data

Results: Our results showed that there was no statistically significant increase in antenatal complications despite there being an increase in the total number of patients during the same time period. There was however a significant increase in unregistered cases $p<0.0001$. There was also a statistically significant increase in the total number of lscs and normal deliveries $(\mathrm{p}=0.03)$.

Conclusions: Our analysis concludes that despite there being an increase in the total number of cases compared to the previous year there was no statistically significant increase in complications.

There was however a significant increase in unregistered cases which may be due to increased referrals from PHCs. The increase in work load perceived by the doctors may possible be due to stress and the added burden of managing COVID-19 positive patients.
\end{abstract}

Keywords: Abnormal presentations, Antenatal care, High risk, Maternal mortality, Referred cases

\section{INTRODUCTION}

According to World Health Organization (WHO), 800 women per day die due to pregnancy related complications, which may either be present during antenatal period or complications during childbirth. ${ }^{1,2}$ One in seven Indian women do not receive antenatal care. Out of these $4.9 \%$ did not find transportation and $2.9 \%$ did not have access to female health care workers. ${ }^{3}$ This was in the pre-covid era. One can only imagine that this situation could not have improved after the added restrictions due to the COVID-19 pandemic. On an average India records, 2.7 crore pregnancies a year. During the nationwide lockdown imposed in late march 2020 , government records were missing $76 \%$ pregnant women and $83 \%$ newborns. ${ }^{34}$

The aim of this study was to determine whether restricted access to health care and reduced mobility during the lockdown has led to an increase in antenatal complications and high risk obstetrics. 


\section{METHODS}

Retrospective analysis of records was carried out at MGM Medical College, Kalamboli from 23rd march 2020 to 22nd June 2020 and 23rd March 2019 to 22nd June 2019. The data was divided into 2 groups patients admitted between 23rd March 2020 to 22nd June 2020 were taken as study group and data from records of the same time periods last year that is 23rd March 2019 to 22nd June 2019 as control group. Inclusion criteria- All pregnant patients admitted in our unit during the specified time period. Exclusion criteria - Post natal patients and COVID-19 positive patients were excluded from this study. The incidence of antenatal complications and mode of delivery were analyzed. Neonatal complications were also compared. The patients were matched for age, gender and parity.
There was no active patient involvement in this particular study analysis of hospital records was carried out after due permission from institutional ethical committee.

Data was collected from registers meticulously maintained by staff. The statistical significance was kept as $\mathrm{p}<0.05$.

Statistical analysis was carried out using standard statistical formulas with SPSS version 21.

\section{RESULTS}

There was an overall $26 \%$ increase in the total number of hospital admissions between the two study periods. (Table 1)

Table 1: Antenatal complications in patients.

\begin{tabular}{|c|c|c|c|c|}
\hline Antenatal complications & $\begin{array}{l}\text { Control group } \\
(\mathbf{n}=780)\end{array}$ & $\begin{array}{l}\text { Study group } \\
(\mathbf{n}=1057)\end{array}$ & $\%$ of increase & $P$ value \\
\hline Hyperemesis gravidarum & 10 & 2 & -1.01 & 0.0041 \\
\hline Bleeding PV before 28 weeks & 1 & 3 & 0.163 & 0.4794 \\
\hline Pre eclampsia/eclampsia & 46 & 60 & -0.22 & 0.8409 \\
\hline Antepartum hemorrhage & 11 & 16 & 0.11 & 0.8555 \\
\hline Abnormal presentation (Breech, Transverse lie) & 23 & 45 & 1.3 & 0.1420 \\
\hline PROM & 15 & 30 & 0.938 & 0.2098 \\
\hline Preterm labour & 29 & 44 & 0.45 & 0.6296 \\
\hline Intrauterine fetal death & 44 & 64 & 0.414 & 0.7094 \\
\hline Unregistered patients & 159 & 341 & 13.26 & $<0.0001$ \\
\hline
\end{tabular}

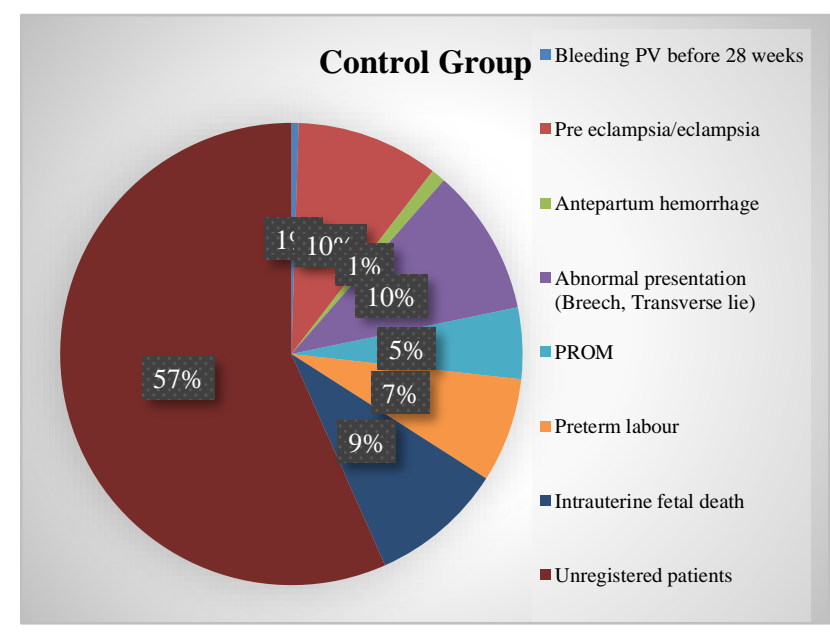

Figure 1: Pie chart depicting antenatal complications in control group (23rd March 2019 to 22nd June 2019).

There was a $0.16 \%$ increase in cases with antepartum hemorrhage between control and study group $(\mathrm{p}=0.163)$. There was a $0.11 \%, 1.3 \%, 0.98 \%$ and $0.45 \%$ increase in antepartum hemorrhage, abnormal presentations, PROM and preterm labour respectively between control and study group, however this difference was not significant( $\mathrm{p}=0.85,1.42,0.20$ and 0.629 ). There was a reduction in cases admitted for hyperemesis gravidarum and eclampsia/preeclampsia ( $1.01 \%$ and $0.22 \%$ respectively). The reduction in hyperemesis gravidarum was statistically significant $(\mathrm{p}=0.0041)$.

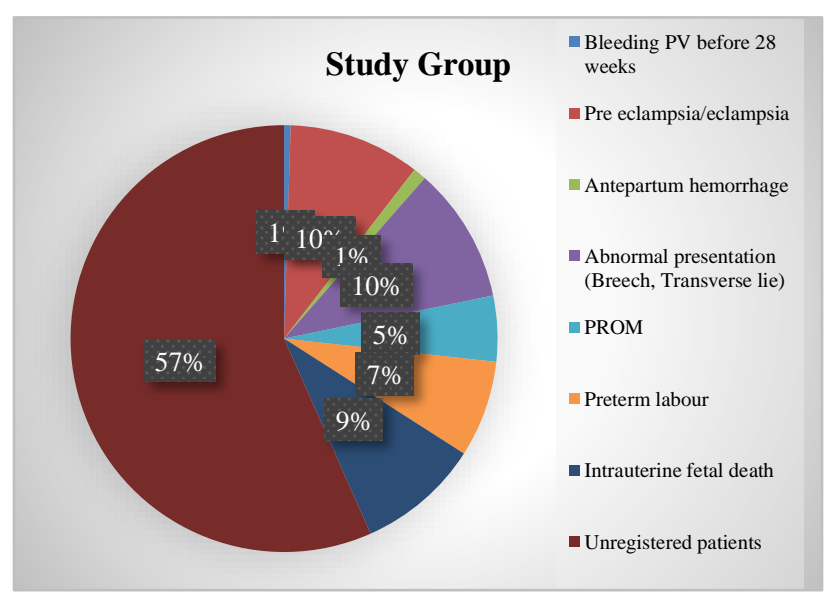

Figure 2: Pie chart depicting antenatal complication in study group (23rd march 2020 to 22nd June 2020). 
Table 2: Mode of delivery and feto-maternal outcome in Covid-19 negative patients.

\begin{tabular}{|lllll|}
\hline $\begin{array}{l}\text { Type of delivery and feto- } \\
\text { maternal outcome }\end{array}$ & Control group $(\mathbf{n = 7 8 0})$ & Study group $(\mathbf{n = 1 0 5 7 )})$ & $\begin{array}{l}\text { \% of } \\
\text { change }\end{array}$ & P value \\
\hline Normal delivery & 509 & 638 & 5.34 & 0.0322 \\
\hline LSCS & 271 & 419 & 5.64 & 0.0322 \\
\hline Instrumental delivery & 08 & 04 & 0.64 & 0.0888 \\
\hline Maternal death & 2 & 8 & 0.506 & 0.1496 \\
\hline
\end{tabular}

Table 3: Neonatal complications.

\begin{tabular}{|lllll|}
\hline Fetal outcome & Control group $(\mathrm{n}=\mathbf{7 8 0})$ & Study group $(\mathrm{n}=\mathbf{1 0 5 7})$ & $\begin{array}{l}\text { \% of } \\
\text { change }\end{array}$ & P value \\
\hline $\begin{array}{l}\text { Neonate with low APGAR } \\
\text { score or NICU admission }\end{array}$ & 50 & 70 & 0.212 & 0.8556 \\
\hline Still birth & 2 & 6 & 0.317 & 0.3167 \\
\hline
\end{tabular}

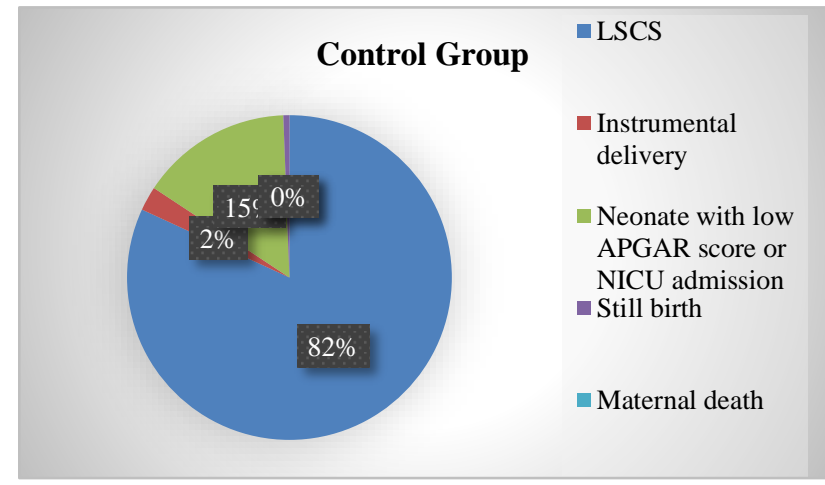

Figure 3: Pie chart depicting mode of delivery and feto- maternal outcome in control group.

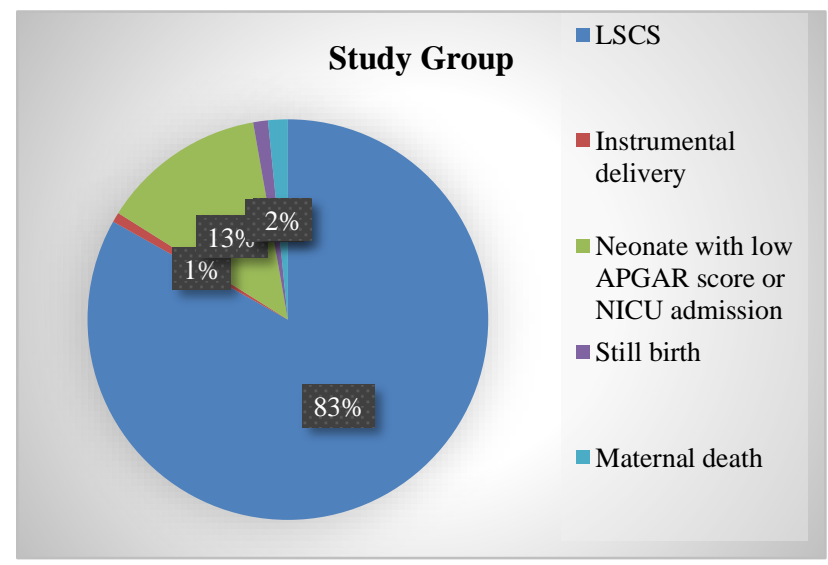

Figure 4: Pie chart depicting mode of delivery and feto- maternal outcome in study group.

There was also a significant increase in the number of unregistered patients $(13.26 \%, \mathrm{p}<0.0001)$ between control and study group). There was an increase in Intrauterine fetal death $(0.41 \%)$ however this was not statistically significant $(\mathrm{p}=0.70)$. In our study overall there was no significant increase in antenatal complications between the two groups.
When comparing mode of delivery there was a statistically significant increase in both vaginal delivery and cesarean section between the two groups (5.34\% and $5.64 \%$ respectively, $\mathrm{p}=0.032$ ). There was however no statistically significant increase in instrumental deliveries, neonatal NICU admissions due to low APGAR score and still births $(\mathrm{p}>0.05)$. There was also no significant increase in maternal deaths $(0.506 \%, \mathrm{p}=0.149)$.

\section{DISCUSSION}

There was a general perception of increase in high risk obstetric cases and complications in antenatal patients in COVID negative patients during the lockdown period. We aimed to determine whether was any actual statistical difference by analysing the data between 23rd march 2020 to 22 nd June 2020 and comparing it to the previous year 2019. A retrospective cohort study was carried out at MGM medical College and hospital, Navi Mumbai a total of 1837 patients were analysed.

The following parameters were compared- Antenatally incidence of hyperemesis gravidarum, bleeding pv before 28 weeks, Preeclampsia/eclampsia, Antepartum hemorrhage, Abnormal presentation, PROM, Preterm Labour, Intrauterine fetal death and number of unregistered patients were noted. Maternal and neonatal complications along with mode of delivery and need for instrumentation were noted.

A study conducted in Jordan demonstrated disruption of antenatal services with significant increase in the percentage of pregnant women not receiving antenatal care from $4 \%$ to $59.53 \%$ ( $\mathrm{p}<0.001)$ during the lockdown period. ${ }^{5}$ Another study demonstrated a reduction of $45.1 \%$ in institutional deliveries $(\mathrm{P}<0.001)$, an increase of 7.2 in high-risk pregnancy, and 2.5-fold rise in admission to the intensive care unit of pregnant women during the pandemic. ${ }^{6}$ The reason for this was believed to be due to fear of getting infection and lockdown by the government. 
Our results show that while there may have been apparent increase in workload and strain on the obstetrician during this stressful time period there was no statistical increase in patient complications. The restricted mobility and access to healthcare could have led to an increase in antenatal complications however no such difference was found in our study. There was however a significant increase in the number of unregistered cases $(13.26 \%$, $\mathrm{p}<0.0001$ ) between the study and control group. This could possibly be due to maximum private sectors being shut and most government sectors being converted to COVID centers.

There was also an increase in overall hospital admission $(26 \%)$ as well as LSCS and normal deliveries $(p=0.03)$ compared to previous year during this time period.

Most studies till date demonstrate that pregnant patients are at in increased risk for COVID-19 related complications however mild and negative cases were a better reflector of community spread. ${ }^{7}$

While various studies have demonstrated the economic and social impact of restricted mobility there have not been many studies demonstrating its impact on the health centres. $^{8}$

Our study is unique in aiming to determine the detrimental effects of the pandemic not due to complications of the disease but due to the overall impact it has had on patient transport and heath care access in remote areas.

\section{Limitations}

Due to ours being a tertiary care centre there was a large volume of patients and therefore impact of missing antenatal checkups in development of obstetric complications could not be assessed. Our study analysed the overall difference in antenatal complications and maternal mortality between the two specified time periods however whether the incidence was higher among booked or un- booked patients could not be determined

\section{CONCLUSION}

Our study concluded that while the perception of antenatal complications by the physician may have increased there was no actual statistical increment in complications. There may however have been an increase in physical and mental stress on the clinician this was however not included in the present study. The possibility of acquiring infections, need for extra precautions, lack of recreation and ill health of fellow colleagues could possibly be a cause of this mental strain.

Funding: No funding sources

Conflict of interest: None declared

Ethical approval: The study was approved by the Institutional Ethics Committee

\section{REFERENCES}

1. World Health Organization 10 Facts on Maternal Health. World Health Organization. Available at: http://www.who.int/features/factfiles/maternal_healt h/en/..

2. Say L, Chou D, Gemmill A, Tunçalp Ö, Moller A, Daniels J.e et al. Global causes of maternal death: a WHO systematic analysis. The Lancet Global Health. 2014;2(6):e323-33.

3. International Institute for Population Sciences (IIPS) and ICF. 2017. National Family Health Survey (NFHS-4), 2015-16: India. Mumbai: IIPS.

4. KK S. Missing in lockdown: Lakhs of pregnant women and newborns. The Federal. 2020:1. Available at: <https://thefederal.com/health/missingin-lockdown-lakhs-of-pregnant-women-andnewborns/> [Accessed 19 February 2021].

5. Muhaidat N, Fram K, Thekrallah F, Qatawneh A, AlBtoush A. Pregnancy During COVID-19 Outbreak: The Impact of Lockdown in a Middle-Income Country on Antenatal Healthcare and Wellbeing. Int J Womens Health. 2020;12:1065-73.

6. Goyal M, Singh P, Singh K, Shekhar S, Agrawal N. Misra S. The effect of the COVID-19 pandemic on maternal health due to delay in seeking health care: Experience from a tertiary center. International $\mathrm{J}$ Gynecol Obstetr. 2020.

7. Centers for Disease Control and Prevention. 2021. COVID-19 And Your Health. Available at: https://www.cdc.gov/coronavirus/2019-ncov/needextra-precautions/pregnancy-breastfeeding.html\#. Accessed on $20^{\text {th }}$ December 2020.

8. Bonaccorsi G, Pierri F, Cinelli M, Flori A, Galeazzi A, Porcelli F. Economic and social consequences of human mobility restrictions under COVID-19. Proceedings of the National Academy of Sciences. 2020:117(27):15530-5.

Cite this article as: Baser A, Kumar S. Impact of pandemic restrictions on antenatal complications at a tertiary care center. Int J Reprod Contracept Obstet Gynecol 2021;10:1468-71. 